\title{
Concepção de clientela: análise do discurso da benevolência no contexto da reforma psiQuiátrica brasileira
}

\author{
Concept of clientele: discourse analysis of the benevolence in the context of the Brazilian psychiatrich reform
}

Concepción de clientela: análisis del discurso de la benevolencia en el contexto de la reforma psiquiatrica brasileña

\author{
Leandro Barbosa de Pinho', Antonio Miguel Bañon Hernández", Luciane Prado Kantorski' \\ 'Universidade Federal de Pelotas. Faculdade de Enfermagem e Obstetrícia. Pelotas, RS \\ "Universidade de Almería. Departamento de Filologia. Almería, Espanha
}

Submissão: 2 1/03/2009

Aprovação: 17/05/2009

\section{RESUMO}

Este estudo pretende conhecer o contexto dinâmico e controverso onde ocorre a prática em saúde mental. Para isso, analisou-se o discurso de trabalhadores de saúde mental sobre a concepção da clientela do serviço. O corpus deste trabalho é composto por entrevistas aplicadas a 17 dos 25 profissionais de saúde mental Que trabalham em um serviço substitutivo de uma cidade da Região Sul do Brasil. O referencial teórico-filosófico foi a Análise Crítica do Discurso. O dispositivo metodológico Que subsidiou a sistematização dos dados foi o "diagrama axiológico-discursivo". Os resultados demonstram que os trabalhadores assumem relações de benevolência em função da indefinição conceitual sobre a clientela do serviço, fruto da dificuldade em estabelecer o Que é normal e patológico em saúde mental. Esperamos que o estudo contribua para problematizar o processo de consolidação da reforma psiQuiátrica brasileira.

Descritores: Estudos da linguagem; Saúde mental; Ciências sociais; Enfermagem psiquiátrica.

\section{ABSTRACT}

This study aims to know the dynamic and controversial which is the practice in mental health. For that, it's analyzes the discourse of workers of mental health about the concept of on the concept of the clientele of the service. The corpus of this work is composed for interviews applied to 17 of the 25 professionals of mental health who work in a service substitute of a city of the Brazilian South Region. The theoretical-philosophical referential was the Critical Discourse Análisis. The methodological device was the "axiologic-discursive diagram". The results demonstrate that the workers assume relations of benevolence because the clientele conceptual undefinition, fruit of the difficulty in establishing what is normal and pathological in mental health. We wait that the study it contributes to problematize the process of consolidation of the Brazilian psychiatric reform.

Key words: Language studies; Mental health; Social sciences; Psychiatric nursing.

\section{RESUMEN}

Este estudio pretende conocer el contexto dinámico y contradictorio en la práctica de salud mental. Para eso, se ha analizado el discurso de los trabajadores de salud mental sobre la concepción de la clientela del servicio. El corpus del trabajo es compuesto por entrevistas aplicadas a 17 de los 25 profesionales que trabajan en un servicio sustitutivo de una ciudad de la Región Sur de Brasil. El referencial teórico-filosófico fue el Análisis Crítico del Discurso. El dispositivo metodológico fue el "diagrama axiológico-discursivo". Los resultados demuestran que los trabajadores asumen relaciones de benevolencia por la indefinición conceptual de la clientela, resultado de la dificultad de establecer lo que es normal y patológico en salud mental. Esperamos que este estudio pueda contribuir para problematizar el proceso de consolidación de la reforma psiQuiátrica brasileña.

Descriptores: Estudios del lenguaje; Salud mental; Ciencias sociales; Enfermería psiQuiátrica.

AUTOR CORRESPONDENTE Leandro Barbosa de Pinho. Rua General Osório, 63I Apto 703. CEP 96020-000. Pelotas, RS.

E-mail: lbpinho@uol.com.br 


\section{INTRODUÇÃO}

Tradicionalmente, no campo da saúde mental, ainda acompanhamos o trabalho organizado para a produção de saúde tendo por base uma concepção organicista do processo saúdedoença. Essa concepção de corpo, mente e espírito, suas dissociações e irregularidades levaram à construção de práticas voltadas para a intervenção nos sintomas e sinais apresentados pelos sujeitos. Sujeitos estes Que eram, muitas vezes, internados em instituições especializadas, destinadas a controlar, supervisionar, conter e tratar essas manifestações ${ }^{(1)}$.

A loucura, como fenômeno da existência, ao ser compartimentalizada num conhecimento médico impessoalizante, transformou o sujeito em paciente, obrigou-o a carregar o rótulo da limitação, da periculosidade e da impaciência, sendo este afastado do contato com as pessoas para ser tratado em instituições especializadas. Um sujeito Que perdeu seus direitos à vida, à dignidade, à convivência e à liberdade, em nome daquilo que a psiquiatria consagrou como "doença" o Que deveria ser caracterizado apenas pela incerteza ${ }^{(2)}$.

A relação intrínseca entre o objeto do conhecimento (a loucuradoença) e o objeto da prática (o louco-doente) determinou a existência de diferentes mecanismos de controle, repressão e vigilância às manifestações do louco. Esses conhecimentos, traduzidos ao longo de séculos e trancados nos manicômios, sobrevivem até os dias atuais pela consolidação de seus discursos, excludentes pela ciência médica, os Quais velam o potencial humano para dar vazão a um discurso de que o louco é um ser limitado e incapaz. Incapaz de assimilar comportamentos, de compartilhar experiências humanas e de comandar sua própria vida.

Apesar das dificuldades enfrentadas no cotidiano dos serviços de saúde, o cenário psiQuiátrico brasileiro vem mudando com a difusão dos diferentes dispositivos de atenção substitutivos. Os mais de 1000 (mil) Centros de Atenção Psicossocial espalhados pelo Brasil são prova de Que há uma transformação na estrutura da assistência em saúde mental. A rede de serviços, na Qual o CAPS se insere, vem substituindo a atenção especializada e centrada nas instituições manicomiais, originalmente excludentes, reducionistas e opressoras da vida, da liberdade e da autonomia do sujeito ${ }^{(3)}$.

No entanto, o ato de reformar não pressupõe apenas a substituição de um serviço por outro, ou de um serviço por uma rede. Isso porque transformar uma realidade parte do princípio de envolver todas as dimensões possíveis no processo de mudança (serviços, atores, processos de trabalho, políticas). Mesmo Que se resista ao conformismo e se contemple a mudança, a reforma sobrevive como movimento porque sempre procura subsídios para reinventar o cotidiano, num esforço contínuo de superação dialética ${ }^{(4-5)}$.

Compreendemos Que o exercício da superação dialética no contexto da reforma psiquiátrica é um processo, no Qual estão permeados diferentes atores, instituições, conflitos, embates, saberes e práticas. Essa realidade não só reflete a dinâmica da produção de cuidado em saúde mental atualmente, como também apresenta as diversas dificuldades de um movimento complexo Que busca, no interior e no exterior dos serviços, uma nova imagem social para aquele indivíduo que sempre foi afastado de seu convívio social.
Nesse sentido, objetivamos, com este estudo, conhecer o contexto dinâmico e controverso onde ocorre a prática em saúde mental. Para isso, analisamos o discurso de trabalhadores de saúde mental de um serviço substitutivo, com relação à clientela de atendimento. Procuramos desvelar contradições, conceitos, potencialidades e limitações destacadas pelos discursos dos trabalhadores no conjunto de sua prática cotidiana.

\section{REFERENCIAL TEÓRICO-FILOSÓFICO}

Para este estudo, escolhemos a Análise Crítica de Discurso $(\mathrm{ACD})^{(6)}$ como referencial teórico-filosófico para conhecer o contexto da prática em saúde mental e para analisar os discursos dos trabalhadores. O referencial é produto da articulação de diferentes teorias oriundas das ciências humanas e das ciências linguísticas dos últimos 30 anos, responsáveis por compreender o discurso como produção da sociedade, capaz de modificar o meio, assim como ser modificado nesse processo de interlocução.

A análise crítica de discurso desenvolveu-se como disciplina no campo da análise de discurso a partir de um movimento teóricofilosófico nas ciências humanas denominado "giro lingüístico", o Qual representava certa mudança de paradigma na filosofia e nas disciplinas correlatas, o Qual pressupunha uma reorientação para o próprio conceito de linguagem, como um evento Que não somente "representa" uma realidade, mas como "formadora" delas. Isso Quer dizer Que a linguagem não é produto do meio, mas produtora deste, em contínuo processo de transformação das realidades ${ }^{(7)}$.

A perspectiva crítica da análise de discurso teve como influência principal a "lingüística crítica", uma corrente teórica dos estudos da linguagem em articulação com as ciências sociais críticas, baseadas principalmente nos pressupostos filosóficos da Escola de Frankfurt. A análise crítica de discurso busca a identificação de elementos discursivos específicos Que possam estimular ou romper com certas estruturas cristalizadas de poder e ideologia. Nesse sentido, ela é crítica por ser dialética, além de ser um método de análise Que permite atribuir significados a eventos sociais específicos marcados, muitas vezes, pela relação vertical, pelo poder, pela subversão e pela normalização( ${ }^{(6)}$.

Um exemplo de como os significados do discurso podem servir para diferentes finalidades na sociedade está na constituição do discurso psiquiátrico no século XIX. O discurso psiQuiátrico nesse período não se caracterizou por objetos privilegiados, mas pela maneira de como esses objetos foram formados pela medicina. Para poder falar de tais objetos, foi necessário elevar o discurso ao nível da prática social, pois o discurso só pode "formar" objetos Quando estes puderem ser abordados, nomeados, analisados, classificados e explicados. Foi assim que se criou uma unidade dos discursos sobre a loucura. A medicina mental foi capaz de defini-la como dimensão patológica não en@uanto saber, mas enфuanto prática, ou seja, a loucura como constituinte de mecanismos de repressão, de jurisprudência, de compreensão teológica, de objeto do diagnóstico nosológico e das descrições patológicas. Sendo assim, o discurso não é uma representação de elementos, mas constitui-se em práticas, Que formam sistematicamente os objetos de oue fala ${ }^{(8)}$.

No campo da saúde, em processo de transformação, a loucura foi destrancada do isolamento e re-inserida na comunidade, onde 
ela nasceu e onde deveria ser tratada. Nos serviços de saúde mental Que se propõem a trabalhar com a loucura e com o louco na comunidade, como os CAPS, há o nascimento de novos discursos, responsáveis pelo redimensionamento da prática a partir da construção de novas teorias, sendo um desafio permanente para o movimento da reforma psiquiátrica brasileira. Discursos novos Que, no entanto, também estão permeados de contradições, muitas vezes marcadas pela mescla de modelos de atendimento incompatíveis para a realidade atual de cuidados. Neste estudo será possível observar algumas dessas particularidades com relação ao discurso sobre a clientela de atendimento do CAPS.

\section{PERCURSO METODOLÓGICO}

Trata-se de uma pesquisa de abordagem Qualitativa. O corpus deste trabalho é composto por entrevistas aplicadas pelos pesquisadores, no período de 17/07/2006 a 15/08/2006, a 17 dos 25 trabalhadores de saúde mental Que trabalham em um serviço substitutivo de uma cidade da Região Sul do Brasil e Que se dispuseram a participar da peşuisa. O serviço investigado é um CAPS II, referência para o atendimento em saúde mental na microrregião em Que se encontra.

Entre os profissionais entrevistados, destacam-se: um médico psiquiatra, três psicólogos, um enfermeiro, dois assistentes sociais, dois terapeutas ocupacionais, três auxiliares/técnicos de enfermagem, um farmacêutico, um agente de saúde pública, um oficial administrativo, um vigilante e um servente.

Foram aplicadas três perguntas-chave, conforme roteiro previamente estabelecido. As entrevistas foram gravadas em fitas cassete e, depois de concluídas, encaminhadas a dois digitadores diferentes, responsáveis pela transliteração das gravações.

Nos estudos do discurso, a transcrição concentra-se na descrição detalhada de todos os fenômenos semióticos envolvidos nas conversações, como: pausas, entonações, corte de sílabas ou sinais verbais/não verbais. No caso da transliteração, compreende-se a transcrição dos signos lingüísticos, mas utilizando-se uma ortografia convencional para descrever apenas os enunciados produzidos pelos falantes, sendo o nível mais comum de representação de todos os corpus orais ${ }^{(9)}$.

Os dados foram organizados conforme o dispositivo chamado de "Diagrama Axiológico-Discursivo"(10). Essa metodologia foi desenvolvida no intuito de encontrar certo padrão discursivo nos informantes, ou seja, um "discurso prototípico", Que, por ser naturalmente valorativo, já Que agrega juízos de valor a comportamentos ou ações humanas, está inserido no âmbito da axiologia. No caso dos usuários, a finalização do processo de sistematização metodológica levou à identificação do discurso da "benevolência". Trata-se de um padrão ideológico do trabalhador Que valoriza a experiência limitante da loucura, dando pouca ênfase às Questões mais complexas Que envolvem a autonomia, a liberdade e a contratualidade do louco no cotidiano das práticas e de suas relações interpessoais.

A partir da identificação desse discurso prototípico, a análise dos dados foi em busca das estruturas linguísticas Que mais caracterizassem a dimensão discursiva, as Quais são exploradas mais adiante. Não foi necessário reproduzir fragmentos discursivos de todos os trabalhadores. Optamos por apresentar apenas o discurso mais representativo da dimensão axiológica analisada (a benevolência).

O projeto foi submetido previamente a avaliação pelo Comitê de Ética em Pesquisa da Faculdade de Medicina da Universidade Federal e Pelotas (UFPel), obtendo parecer favorável ao seu desenvolvimento (Ofício 074/2005). Foi, também, garantido o anonimato dos sujeitos do estudo e respeitados todos os preceitos ético-legais que regem a pesQuisa com seres humanos, como é preconizado pelo Ministério da Saúde (Resolução 196/96 do Conselho Nacional de Saúde) e Código de Ética dos Profissionais de Enfermagem.

\section{RESULTADOS E DISCUSSÃO}

A análise dos resultados evidenciou Que os trabalhadores ainda estão procurando uma definição precisa para a clientela de atendimento, a Qual possui uma relação intrínseca com o conceito de normalidade e de patologia em saúde mental. A partir do modo como percebem as Questões mais complexas Que envolvem a loucura no cotidiano, eles também percebem Quem é o potencial usuário do sistema. Um usuário ora tratado como uma pessoa, um indivíduo com direitos, ora como um transtorno, um diagnóstico, responsável por gerar limitações importantes para a convivência pacífica desse usuário em sua comunidade.

O termo "usuário" não é absoluto e tem sido criticado no contexto da saúde. O termo foi introduzido na legislação do Sistema Único de Saúde no sentido de destacar o protagonismo de alguém chamado, anteriormente, de "paciente". A expressão acabou sendo utilizada no contexto da saúde mental para referir-se ao indivíduo com sofrimento mental. No entanto, no campo da reforma psiQuiátrica, o termo "usuário" ainda parece manter certa relação do indivíduo com um serviço de saúde, Quando o importante seria tornar o indivíduo, e não o serviço, o protagonista da relação ${ }^{(11)}$.

Os trabalhadores parecem compreender o modo de operar no interior do serviço substitutivo, no entanto, com dificuldades na sistematização de determinados conhecimentos complexos (louco e loucura, por exemplo), dos Quais o modo de operar é dependente. Essas dificuldades transparecem, no discurso, a partir de relações discursivas e figuras de linguagem, sendo a "sinédoque" a que mais caracteriza essa indefinição. O fragmento inicia com o Questionamento do investigador, e, a seguir, o posicionamento do trabalhador:

Investigador - Eu vou te fazer cinco perguntinhas, né? E ai diante delas a gente vai discutindo algumas coisas, né? Me fala sobre o atendimento do serviço em primeiro lugar. Do atendimento do serviço, como é Que funciona, Qual é o objetivo...

Trabalhador - Bom... então, o atendimento dentro do CAD é como se fosse um hospital-dia, né? em que as pessoas vêm e passam o dia aqui...é/é atendido vários tipos de patologias...é...o nosso perfil de clientes geralmente são usuários com...em estado psicótico, né? Se investiga se tem internações ou não, se tão em crises, na verdade as Que estão nesse perfil tem sido discutido várias vezes assim, né? Desde Que eu cheguei, já foram discutidos algumas vezes mas no geral é... tem que estar em estado psicótico... 
Inicialmente, ao ser Questionado sobre o atendimento do serviço em geral, o trabalhador começa explicitando a Questão do perfil de atendimento da clientela. Parece existir uma correspondência entre o usuário atendido e o perfil, o Qual se estabelece não pelo Que "está posto" como norma, mas por aQuilo Que os trabalhadores julgam, operam e não compreendem em sua totalidade (o conceito de loucura). Isso porQue, nessa situação, a norma está presente e faz parte da rotina dos trabalhadores, e é ela Que comanda determinado modo de organização e sistematização do cuidado, assim como a própria concepção do usuário do sistema.

A conseqüência desse relacionamento complexo com a loucura está exposta no uso figurativo da linguagem, onde há transferência de significados para caracterizar o usuário, mas todos eles estão unidos por uma única relação (a loucura).

Embora a sinédoque faça parte do corpo de conhecimentos retóricos da linguagem e tenha funções originalmente trópicas, substituindo termos Que possuem a mesma significação, aQui ela não somente assume essa função, como também realiza transferências, gerando novos sentidos à realidade. Por exemplo, Quando o usuário é conhecido inicialmente como "pessoas", num apontamento coletivo para resgatar indivíduos singulares por existência, este mesmo sujeito acaba perdendo suas características mais intersubjetivas para fazer parte de novas concepções, desta vez inanimadas, no decorrer do processo de sua adequação às normas e rotinas institucionais (um diagnóstico). Um diagnóstico Que não está dito, mas é dito, revelando o potencial do serviço em adequar-se à clínica tradicional, onde há redução dos sujeitos em "problemas", Que devem ser manejados e tratados na sua organicidade ("várias patologias").

O fato de haver uma fragmentação ideológica do sujeito no interior do serviço em diferentes partes faz parte do Que se pode chamar de uma característica "convencional" das formas simbólicas. Isso Quer dizer Que a produção, construção ou emprego de Quaisquer formas simbólicas, bem como a sua interpretação pelos diferentes atores na interação, são processos Que envolvem a aplicação de regras, códigos ou convenções. Essas regras, códigos ou convenções, por sua vez, seguem rotinas gramaticais, figurativas, sintáticas ou semânticas, aplicadas a uma situação prática para a Qual não necessariamente os atores precisam estar conscientes. Elas fazem parte de um conhecimento tácito Que os indivíduos memorizam no curso de suas vidas, criando novas expressões e recriando sentidos daquelas já manifestadas por outros ${ }^{(12)}$.

A loucura não existe na história da humanidade como conceito isolado, em seu estado selvagem. Ela existe porque faz parte de uma determinada sociedade, ela não existe fora das normas da sensibilidade Que a isolam, nem das formas de repulsa que a capturam ou a excluem. Isso Quer dizer Que o conhecimento humano sobre a loucura nasceu a partir dos movimentos rudimentares da experiência, Que a captura como saber. Mas essa mesma experiência ainda não é a loucura em si, é apenas uma divisão desta, a Qual foi convencionada pelo homem para servir-lhe como seu objeto de estudo ${ }^{(13)}$.

Mesmo que pareça haver (e não pareça haver ao mesmo tempo) certo "consenso" sobre os conceitos de loucura e de louco, apoiados na clínica tradicional psieuiátrica (o diagnóstico, a patologia, a crise, o surto, o paciente), parece natural Que os trabalhadores reproduzam, na prática, o conhecimento compartimentalizado da teoria. Caracterizada como falta e erro, como desvio e excesso e como experiência limitante, aos poucos a clínica vai conformando a proposta política, a política vai conformando o serviço, o serviço vai conformando a prática dos trabalhadores e estes vão conformando o atendimento à clientela:

Investigador - Me explica um pouQuinho, então, o que que tu consideras como normalidade, né? Que...

Trabalhador - Não há um termo muito correto eu acho assim entendeu, né? Foi o que me veio na mente agora. Cada um... não é o que é dentro da normalidade, mas o que aquele/aquele ser consegue fazer, entendeu? Dentro da sua capacidade, né? Dos seus limites, da tua, né? Que normal acho que é uma coisa Que...depois que entrei aqui eu não tenho mais esse conceito do que é normal e de que não é normal, né? Mas dentro do que aquela pessoa consegue desenvolver, né? Dos limites, né? Da sua capacidade... então Que aquela pessoa, né? Tu trabalha a capacidade pra que ela consiga ter uma autonomia um dia, ter uma vida mais livre assim, né? Não tão dependente das pessoas, dos outros, né?

Parece não ser fácil para os trabalhadores descrever o Que é normal e patológico em saúde mental. Por ser um evento complexo e por situar-se totalmente no terreno da abstração, o sujeito se utiliza de uma ferramenta lingüística chamada de metadiscurso, a Qual revela as dificuldades de explicação de determinados eventos. Um metadiscurso não se trata de um recurso estilístico da linguagem, pois ele está imerso nos contextos sociais como mecanismo fundamental para desvendar as interações sociais e seus efeitos de sentido. Entretanto, um metadiscurso só adquire um significado Quando incorporado a um contexto específico, em Que leitor e escritor (ou entrevistador e entrevistado no caso de discursos orais como este) constroem, juntos, a materialidade ideológica da linguagem ${ }^{(14)}$.

Esses metadiscursos funcionam como estruturas de linguagem Que procuram amenizar, intensificar, eliminar ou corrigir Questionamentos ou reações surgidas pelos sujeitos em interação. É dizer Que o metadiscurso avalia-se a si mesmo, corrige-se, intensifica determinados enunciados, deixando Que estes se expressem por si mesmos para revelar o potencial dialógico da interação. No contexto estudado, o sujeito tenta "ser compreendido", ao ser estimulado a falar de eventos normalmente "incompreensíveis". Como se fosse necessário provocar uma nova busca pelo sentido da mensagem, ficando claro o Quanto o falante procura interagir com o receptor para compartilhar essas mensagens.

No fragmento destacado, o sujeito começa com o metadiscurso como elemento fundamental, para depois introduzir suas reflexões. Esses metadiscursos produzem variações semânticas ao longo do discurso analisado. Quando Questionado sobre o significado da normalidade em saúde mental, procura antecipar um possível erro de interpretação ${ }^{(15)}$, dizendo: "eu acho assim, entendeu, né?". Nessa situação destacada, ao dizer Que "acha assim", o sujeito está tentando repassar um significado singular para um conhecimento abstrato de difícil significação (o normal e o patológico). Ou seja, nesse momento, o importante não é a avaliação do interlocutor no processo de interação, mas mostrar Que o trabalhador possui uma 
opinião própria sobre o assunto e pode discuti-la, apesar de sua complexidade.

O trabalhador também pretende mencionar Que, estando equivocado ou não, concluiu um raciocínio ao Qual foi estimulado a refletir, utilizando-se de outro metadiscurso desta vez para reafirmar seu propósito ("foi o Que me veio na mente agora"). Vale lembrar Que os elementos metadiscursivos citados estão deslocados na oração para a esQuerda, antes do significado a ser reparado (o fenômeno da topicalização da linguagem). Isso significa Que há uma necessidade de prender a atenção do interlocutor, para justificar-se antes de explicitar própria justificativa.

Inicialmente, como se pode notar, os metadiscursos prenunciam um determinado acontecimento lingüístico (a reflexão do trabalhador sobre o conceito de normalidade). À medida Que o assunto vai adeuirindo consistência, as dúvidas sobre o significado do tema também começam a aparecer. Essas dúvidas se materializam tanto nos fenômenos metalingüísticos como no contexto social. É dizer Que as incertezas sobre a complexidade dos conceitos rondam o discurso por meio de elementos metalinguageiros e repercutem na prática, às vezes, de maneira equivocada, limitada e enviesada.

Os metadiscursos posteriores confirmam a necessidade de autocorreção do conteúdo enunciativo para evitar equívocos na relação comunicacional. $\mathrm{O}$ trabalhador pretende lembrar - por meio de metadiscursos - Que, dentro do campo do normal e do patológico, existem Questões importantes, porém Que merecem diferenciação. Se antes ele se referia ao conceito, agora ele pretende discutir o estado de normalidade. Como se o conceito fosse discutido no plano da abstração e o estado no terreno da prática.

Existe uma dificuldade lógica da psiquiatria em compreender o incompreensível e encarar as interrogações da humanidade. Ela desenvolveu, durante séculos, um corpo de conhecimentos racionalizantes Que pudessem descrever eventos complexos, mesmo Que fragmentassem os sentidos da experiência humana. Trata-se de exercer a dominação sobre algo indomável, exercer poder sobre algo para o Qual o sucesso virou fracasso. Sem dúvida, ainda é natural que os profissionais recorram ao arsenal de uma clínica Que procura realizar diagnósticos impecáveis, mesmo Que objetualizem o sujeito e esQuadrinhem a vida. No entanto, Quando esse diagnóstico se depara com situações Que fogem da nossa realidade mais corrieueira, para o Qual a racionalidade não tem explicações, surgem as incertezas. Nesse sentido, em Que medida a clínica pode atenuá-las Quando, junto com as dores, elas retiram do sujeito sua personalidade, sua livre responsabilidade sobre a vida e a morte? ${ }^{(16)}$.

Importa, numa relação com a loucura, a forma como seus atores desenvolvem estratégias para compreendê-la. Ainda Que o campo da saúde mental respeite definições tradicionais, o fato de o trabalhador compreender Que se deve trabalhar naquilo que o sujeito pode fazer, para Que ele desenvolva o mínimo de autonomia, já é um avanço importante Quando falamos em reabilitação

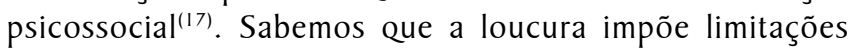
psicossociais ao sujeito, mas é possível tirar proveito dessas limitações a partir de um processo de trabalho Que capte as potencialidades do sujeito. Isso Quer dizer que podemos trabalhar com o estado de normalidade, tão precioso para a clínica tradicional, sem, contudo, esquecer de Que podemos produzir vidas e trocas nos espaços sociais de atendimento.
O trabalhador parece tensionar, no cotidiano de sua prática de atendimento ao usuário, conceitos importantes no campo da saúde mental, como limite e capacidade. Se entendermos o limite como algo imposto pela realidade ou pela condição do sofrimento, mas Que pode ser transformado por não ser totalizante da vida, estaremos contribuindo para a promoção e recuperação do indivíduo, assim como preconiza a reforma psiQuiátrica. Ao contrário, Quando a limitação adQuire sua centralidade no projeto terapêutico e nas práticas dos trabalhadores, estaremos correndo o risco de desenvolver estratégias Que não prejudicam, mas também Que pouco contribuem para a libertação. Isso porQue, ao invés de promover autonomia, autogestão e cidadania, a intervenção passa a ser pautada no compadecimento, na comoção e na benevolência.

No discurso anterior, por exemplo, o entrevistado fala da necessidade de estimular a capacidade do indivíduo para a vida cotidiana, referindo-se à Questão da autonomia. No entanto, esse trabalho parece voltado para o desenvolvimento de certa "capacidade adaptativa" para a vida social, para Que o usuário consiga conviver com o mínimo de dificuldades na comunidade. Ao enxergar mais a limitação do Que a potencialidade, o serviço de novo deixa de re-politizar o sujeito para adequá-lo aos padrões socialmente aceitos e estabelecidos como norma.

Há um conector contra-argumentativo Que confirma esse posicionamento ("mas"). No momento em Que o trabalhador diz Que é importante trabalhar com as diferentes possibilidades do usuário, ele mesmo, logo adiante, estabelece graus de importância para sua própria fala. Desloca-se, portanto, o sentido de o serviço estimular o sujeito para o fato de o mesmo serviço trabalhar "dentro do Que aquela pessoa consegue desenvolver". Ou seja, a prática parece estar voltada para a independência do indivíduo em relação à comunidade, mas contraditoriamente vem estimulando sua dependência em relação ao serviço.

O próximo fragmento do discurso confirma essa tendência de centralização na docilização de corpos e pouco trabalho visando à libertação de sujeitos:

\section{Investigador - Que tipo de clientela vocês atendem?}

Trabalhador - Ah, sim, a nossa clientela o Que Que é? transtorno mental, é esquizofrênico, bipolar e... ah Qual é o outro? Como é que é? Eu não sei direito assim, só sei que é... mais o Que Que eu posso falar pra ti? Ah, tem casos também Que a gente leva o paciente em casa, ta? Então é assim, o familiar não/não tem, ah, condições de trazer, tirando Que eles, né? Tem Que ser o paciente mesmo, se ele não tem condições de sair de casa até o nosso serviço, Que eles ficam inseguros, né? Que eles não conseguem chegar nem no ponto de ônibus, aí a gente vai buscar em casa, aí a gente busca assim, um bom tempo, aí a gente tira e faz o treinamento também, muitos casos a gente já fez treinamento pra eles irem sozinhos e voltarem sozinhos, né? Com o, aí nesse caso assim também tem um grupo Que a gente tenta socializar, porQue muitos a, o familiar não tira eles, né? Não levam eles pra, como é Que eu posso explicar? A/a gente ensina eles o que é banco, a gente leva eles no banco, a gente leva o mais comum, banco/banco, a lotérica, os museus, a gente leva em mercado, a gente leva eles no shopping pra eles terem aquela socialização, e muitas vezes pra eles poderem lidar 
sozinhos porQue o familiar tem muito medo de, ah, mandar ele até numa panificadora, entendeu? São muito, eles protegem demais, né? E não é por aí, por aí a gente faz esse trabalho pra eles poderem se desligarem um pouquinho e ter uma vida, né? Como é Que a gente diz assim? Com mais autonomia, né? É isso aí.

Geralmente existe um conflito de posições entre os trabalhadores de saúde mental no Que tange ao diagnóstico e às concepções do objeto de cuidado na área. Muitos profissionais fazem uma distinção entre o que seria de domínio da psicopatologia e da ordem do social. Parece haver dificuldades em sistematizar conhecimentos e práticas Que possibilite interpretar sintomas como manifestações comportamentais e inscritas num contexto sociocultural. Chega-se a pensar que um sintoma pode ser uma resposta da desordem social, mas pouco se trabalha visando identificar esses determinantes, como avaliar a família ou a comunidade nesse contexto. Isso, por sua vez, reduz o potencial de intervenção terapêutica do serviço como um todo ${ }^{(18)}$.

Nesse sentido, os trabalhadores se encaixam em três grupos distintos de assistência. No primeiro grupo, fazem parte os profissionais Que trabalham num "modelo psicossocial com ênfase na instituição". Trata-se de um grupo centrado numa concepção psicossocial de cuidado, mas num fazer institucionalizado, pouco orientado por práticas territoriais. Num segundo grupo, inseremse os trabalhadores orientados pelo modelo territorializado, Que valorizam as experiências subjetivas dos sujeitos e não os desvincula da comunidade e da família, além de mostrarem-se preocupados com as esferas jurídico-política do mesmo. E o terceiro grupo é formado pelos trabalhadores orientados por um "modelo biomédico humanizado". Nesse modelo, há uma ênfase na psicopatologia, com enfoque no cuidado assistencialista e muitas vezes tutelar, com posturas pedagógicas muitas vezes verticalizadas, com práticas voltadas para o reposicionamento de manifestações, para Que sejam compatíveis com a reinserção social. Nesse caso, os trabalhadores desenvolvem a humanização do ponto de vista da esfera tutelar, com ações normalizadoras e pouco críticas sobre a vida, as relações humanas e o próprio sentido do cuidado ${ }^{(18)}$.

Discutimos anteriormente o fato de o trabalhador levantar recursos lingüísticos para realizar transferências semânticas (como a sinédoque), principalmente no que tange ao conhecimento sobre a clientela do serviço. Nesse fragmento em especial, a sinédoque também está presente, assim como algumas estruturas metadiscursivas e alguns marcadores discursivos, especialmente os de substituição.

No caso do metadiscurso, o trabalhador seguidamente faz referências ao fato de Que assume determinadas responsabilidades com o usuário Que seriam, conforme diz, da família. Por exemplo, afirma Que o serviço acompanha o "paciente" ao banco, ao ponto de ônibus, ao museu, busca em casa e leva ao shopping. No entanto, ao mesmo tempo em Que executa essas atividades, ele mesmo não parece ter certeza da finalidade de seu próprio trabalho, evocando elementos do tipo: "o que que eu posso falar pra ti?", "como é que eu posso explicar?" e "como é que a gente diz assim?".

Esses elementos lingüísticos aqui funcionam como tentativas de reformulação de seu próprio enunciado, como se o sujeito estivesse buscando novos conhecimentos para encaixá-los dentro de uma mesma seqüencialidade discursiva. Dito de outra forma, demonstram o euanto o trabalho com a loucura ainda é incerto para ele, principalmente nos aspectos relacionados à reabilitação psicossocial.

"Aquela socialização", por exemplo, para o trabalhador, diz respeito à prática de acompanhar o usuário nos ambientes sociais, de ensiná-lo a comportar-se nesses locais. Aqui, aparece o recurso da pronominalização, Quando há a substituição do pronome "nós" por "a gente" (típico do contexto coloquial), remarcando a singularização da eQuipe como unidade num evento marcado pela oralidade (a entrevista).

Compreendemos que, embora se deva considerar o fato de que o serviço esteja preocupado com o processo de ressocialização do sujeito, não é levando o louco para passear Que estaremos promovendo socialização. "Aquela socialização" entendida pelo profissional não é compatível com "aQuela socialização" Que conhecemos e defendemos como princípio ideológico da vida. Quando se leva ao indivíduo ao banco, à lotérica, ao museu, tendo por base apenas um treinamento de suas habilidades sociais ou uma convivência superficial com a sociedade, continua-se adestrando o indivíduo, buscando sua docilização. Nesse caso, voltaremos aos tempos em que Pinel desenvolveu as bases de seu tratamento moral como único e eficaz recurso pedagógico responsável pela recuperação das habilidades sociais do louco. Ensiná-lo a exercer as atividades fundamentais da vida cotidiana não Quer dizer Que estamos promovendo autonomia. Ao contrário, poderá reforçar o imaginário social com o compadecimento, a comoção e a pena, como sentimentos e práticas Que substituem a solidariedade, o compartilhamento, o respeito mútuo e a necessidade de valorização dos potenciais humanos.

Portanto, reside aqui uma das grandes dificuldades em construir as pontes entre conhecimentos que se aproximam e se distanciam ao mesmo tempo. A fronteira entre o Que é normal e o Que é patológico já é imprecisa por natureza para indivíduos considerados simultaneamente, mas é perfeitamente precisa para um único indivíduo e mesmo indivíduo considerado sucessivamente. Aquilo Que é posto como normal, mesmo Que "normalizado", pode ser patológico em outra ocasião, se permanecer inalterado. Isso porQue o normal é o efeito obtido pela norma manifestada no ato. Só Que Quem avalia essa condição é o próprio indivíduo, porque é ele que sofre com a incapacidade e com a insuficiência do momento. Portanto, é preciso entender que o fenômeno patológico transforma a personalidade do doente, para não correr o risco de ignorá-lo ${ }^{(19)}$.

A loucura e o louco, tensionados no contexto do processo saúdedoença e institucionalizados na linguagem dos atores sociais, parecem suspendidos e pouco repensados como eventos da existência material. Ao serem assumidos por uma roupagem clínica Que os absorvem como "diagnóstico", Que os transforma em limitação e incorpora, no plantel de suas práticas, a benevolência, o compadecimento e a comoção como medidas tutelares, os trabalhadores se distanciam do sujeito singularizado que busca, no serviço, um sentido e uma possibilidade para problematizar a sua vida. Mais do eue isso, ao distanciar-se do sujeito, o trabalhador parece distanciar-se da possibilidade de compartilhar o cuidado, ou seja, como um processo de relacionamento constituído com o outro e não para ele, envolvendo contratualidade e negociação coletiva. 
O cuidado oferecido pelas instituições de saúde mental se torna pedagogicamente potente Quando promove a interação, o respeito, a renovação e a re-invenção daQuilo Que muito tempo foi esQuecido pela chancela do hospital psiQuiátrico: o humano. Isso porque aQueles serviços Que agregam pouco valor às experiências humanas e reduzem determinadas experiências subjetivas a um corpo de conhecimentos inanimados tendem a reproduzir os inúmeros "jardins de bonsais" japoneses, onde as plantas são supervisionadas e impedidas de crescer além dos limites pré-estabelecidos pela ação humana sobre o ambiente ${ }^{(20)}$.

Nesse sentido, Quando se trata de "desinstitucionalizar" a loucura, o louco e a própria clínica, fala-se em promover a desfixação do aparato institucional Que movimenta a lógica normativa e prescritiva das instituições e dos conhecimentos. Trata-se de desinstitucionalizar o corpo de saberes produzidos por uma psieuiatria eue dissociou a doença da existência, valorizando mais o sintoma (sobre o Qual se constrói a instituição e determinadas práticas), a fragmentação e a compartimentalidade do Que a singularização. A verdadeira desinstitucionalização será conhecida como processo teórico-práticocrítico Quando reorientar instituições, serviços, saberes, práticas e estratégias em torno do objeto "doença". Assim, ao contrário de centralizar-se na cura, busca-se a emancipação; da reparação à reprodução social de pessoas; do reducionismo à sociabilidade, às redes e à complexidade da vida ${ }^{(21)}$.

No seio da reforma psiQuiátrica, discutimos a apropriação de certos conceitos entendidos pelos trabalhadores e elementos lingüísticos usados no discurso sobre o atendimento do usuário. Entendemos Que a prática dos trabalhadores parecem manifestações dos seus próprios discursos, os Quais disseminam potenciais ideológicos para romper e superar modelos tradicionais de assistência, ao mesmo tempo em Que ficam presos e pouco avançam em termos de estimular a autonomia, a libertação e a contratualidade.

\section{CONSIDERAÇÕES FINAIS}

Este estudo procurou analisar o discurso de trabalhadores de saúde mental sobre a clientela de atendimento (o usuário). Evidenciamos Que muitas das práticas com relação à loucura e ao louco são fruto de um contexto complexo em Que a internalização de conhecimentos novos ainda se mesclam com conceitos tradicionais. Embora os trabalhadores procurem trabalhar com a tentativa de romper com modelos tradicionais de atendimento, eles ainda estão sujeitos a experienciar contradições Que colocam em suspensão sua própria prática no interior dos serviços substitutivos, como é o caso da benevolência.

Vivemos num contexto em Que os conceitos e as práticas procuram destituir conceitos excludentes e reposicionar sujeitos, assim como transformar práticas centralizadoras em prol da horizontalidade e da negociação como premissas fundamentais de tratamento humanizado. Mas o mais importante talvez seja a ressignificação do imaginário social sobre a loucura, Que depende do Que e de como se faz com a loucura no interior dos serviços de saúde mental. Um desafio para o movimento da reforma psiQuiátrica brasileira, bem como para os sujeitos Que fazem a saúde mental no cotidiano dos cuidados.

Esperamos Que este estudo sirva de subsídios para novos estudos na área, de modo a contribuir com a ressignificação de determinados conceitos ainda enraizados em nosso contexto e, ao Que parece, um desafio para serem superados na prática.

\section{REFERÊNCIAS}

1. Paulin LFRS, Turato ER. Antecedentes da reforma psiQuiátrica no Brasil: as contradições dos anos 1970. Hist Ciênc Saúde-Manguinhos 2004; 1 I (2):241-58.

2. Peixoto G. Algumas considerações (com um pouco de história familiar) sobre a relação entre a loucura, a ética e a política no âmbito da saúde mental. In: Amarante PDC, organizador. Archivos de Saúde Mental e Atenção Psicossocial. Rio de Janeiro: NAU; 2003. p. 149-55.

3. Bezerra Júnior B. Desafios da reforma psiQuiátrica no Brasil. Physis: Rev Saúde Coletiva 2007; $17(2): 243-50$.

4. Amarante P. A clínica e a reforma psiquiátrica. In: Amarante PDC, organizador. Archivos de Saúde Mental e Atenção Psicossocial. Rio de laneiro: NAU; 2003. p. 45-65.

5. Silva ATM, Souza IS, Silva CC, Nóbrega MML, Oliveira Filha M, Barros S, et al. Formação de enfermeiros na perspectiva da Reforma Psieuiátrica. Rev Bras Enferm 2004; 57(6): 675-8.

6. Fairclough N. Discourse and social change. $11^{\text {a. }}$ ed. Cambridge: Polity Press; 2006.

7. Gracia TI. O "giro lingüístico”. In: Iñiguez L, organizador. Manual de análise do discurso em ciências sociais.
Petrópolis: Vozes; 2004. p. 19-49.

8. Foucault M. Arqueologia do saber. $7^{\text {a. }}$ ed. Rio de Janeiro: Forense Universitária; 2005.

9. Llisteri J. La representación ortográfica de corpus orales. Barcelona; 2008 [citado em: 13 mar 2009]. Disponível em: http://iceu.uab.cat/ joaQuim/language_resources/ spoken_res/Repres_ortog_corp_oral.html.

10. Pinho LB. Análise crítico-discursiva da prática de profissionais de saúde mental no contexto social da reforma psiquiátrica [tese]. Ribeirão Preto: Escola de Enfermagem de Ribeirão Preto, Universidade de São Paulo; 2009.

11. Amarante P. Saúde mental e atenção psicossocial. Rio de Janeiro: Fiocruz; 2007.

12. Thompson JB. Ideologia e cultura moderna: teoria social crítica na era dos meios de comunicação de massa. $6^{\text {a }}$ ed. Petrópolis: Vozes; 2002.

13. Foucault M. Problematização do sujeito: psicologia, psiquiatria e psicanálise. $2^{\text {a. }}$ ed. Rio de Janeiro: Forense Universitária; 2002.

14. Moraes LSB. O metadiscurso em artigos acadêmicos: variação intercultural, interdisciplinar e retórica [tese]. 
Rio de Janeiro: Programa de Pós-Graduação em Letras, Pontifícia Universidade Católica do Rio de Janeiro;2005.

15. Charaudeau P, Maingueneau D. Dicionário de análise de discurso. $2^{\text {a. }}$ ed. São Paulo: Contexto; 2006.

16. Gadamer HG. El estado oculto de la salud. Barcelona: Gedisa; 1996.

17. Jorge MSB, Randemark NFR, Queiroz MVO, Ruiz EM. Reabilitação psicossocial: visão da equipe de saúde mental. Rev Bras Enferm 2006; 59(6): 734-9.

18. Nunes M, Torrenté M, Ottoni V, Neto VM, Santana M. A dinâmica do cuidado em saúde mental: signos, significados e práticas de profissionais em um Centro de Assistência Psicossocial em Salvador, Bahia, Brasil. Cad Saúde Pública 2008; 24(1): 188-96.

19. Canguilhem G. O normal e o patológico. $5^{\text {a. }}$ ed. Rio de Janeiro: Forense Universitária; 2000.

20. Valentini W. Nenhum ser humano será bonsai. In: Harari A, Valentini W, organizadores. A reforma psiQuiátrica no cotidiano. São Paulo: Hucitec; 200 I. p. I I-24.

21. Rotelli F. A instituição inventada. In: Nicácio F, organizador. Desinstitucionalização. 2a. ed. São Paulo: Hucitec; 200 I. p. 89-90. 